\title{
Avaliação do sistema de gerenciamento de pneus do município de Volta Redonda
}

\section{Evaluation of the system management of tires for the local authority of Volta Redonda}

\author{
1 Marcela Aguiar Portugal Viotti maoceano@hotmail.com \\ 2 Joice Andrade de Araújo \\ 2 Fernanda Augusta de Oliveira
}

1 Graduada em Engenharia Ambiental, Centro Universitário de Volta Redonda, UniFOA.

2 Docente do Centro Universitário de Volta Redonda, UniFOA.

\section{Resumo}

A região de Volta Redonda apresenta grande demanda na utilização de pneus comuns e pneus OTRs, o que acarreta em um aumento de geração de resíduos desse material. Com o aumento do descarte incorreto na região, há uma grande preocupação em reduzir esse passivo ambiental. 0 presente estudo teve por finalidade diagnosticar a destinação dos pneus, por meio de sua trajetória, levando em consideração o fluxo do berço ao túmulo. A metodologia utilizada caracteriza-se como qualitativa, de cunho exploratório, e quanto aos procedimentos, subdivide-se em: pesquisa bibliográfica, estudo de caso, levantamento de dados em campo de pesquisa. Tais procedimentos foram utilizados para a aquisição de dados do sistema de gerenciamento dos pneus inservíveis de Volta Redonda, bem como para identificação da sistemática de gerenciamento vigente desses pneus. Os resultados apontaram todos os aspectos positivos e negativos em relação à destinação final do pneu, para o município de Volta Redonda e os problemas enfrentados para cumprir a forma correta a destinação. Nos aspectos positivos, pode-se observar que, apesar de o município não possuir um sistema de gerenciamento, a Guarda Municipal assumiu o controle do processo. Já no ponto de vista negativo, há um plano de gerenciamento ineficaz por ser realizado por um órgão que não possui essa competência. Outro fator negativo é que, por não possuir uma empresa de reciclagem, há um gasto financeiro maior para o transporte e destinação.

\section{Palavras-chave}

pneu; logística reversa; reciclagem.

\begin{abstract}
The Region of Round Turn presents great demand in the use of common tires and tires OTR's that it brings in an increase of generation of residues of this material. With the increase of the incorrect to descard in the region there is a great preoccupation in reducing these environmental liabilities. The present study had since finality diagnosed the destination of the tires, through his trajectory taking into account the flow of the cradle to the tomb. The used methodology is characterized how qualitative, of hallmark exploratory and as for the proceedings it is subdivided in: Bibliographical inquiry, Case study, Lifting data in inquiry field. Such proceedings were used for the acquisition of data of the system of management of the unserviceable tires of Volta Redonda, as well as for identification of the systematic one of management in force of same. The results pointed to all the positive and negative aspects regarding the final destination of the tire, for the Local authority of Round Turn and the problems faced to carry out the correct form of this destination. In the positive aspects it is possible to observe that in spite of the Local authority it will not have a system of management to City Officer it assumed the control, already in the negative point of view it has a plan of ineffective management to be be carried out by an organ that has not this competence, it is another negative factor what because of not having an enterprise of recycling there is a bigger financial expense for the transport and destination. The Local authority of Round Turn in his plan should have Recycle Station in each district for the collection of these tires if It improved the distribution and efficiency of this collection.
\end{abstract}

\section{Keywords}

Tire; Reverse Logistics ; Recycling.

\section{Como você deve citar?}

VIOTTI, Marcela Aguiar Portugal; ARAÚJO, Joice Andrade de; OLIVEIRA, Fernanda Augusta de. Avaliação do sistema de gerenciamento de pneus do município de Volta Redonda. Cadernos UniFOA, Volta Redonda, n. 33, p. 7-16, abr. 2017. 


\section{INTRODUÇÃO}

Nos dias atuais, percebe-se o aumento significativo da geração de resíduos sólidos e, como decorrência, a grande preocupação com a adequação desses resíduos, bem como a diminuição desse passivo ambiental. Para abranger as exigências da destinação dos resíduos dos pneus, foram criadas duas resoluções: em 1999, foi criada a Resolução CONAMA 258/1999, que "determina que as empresas fabricantes e as importadoras de pneumáticos ficam obrigadas a coletar e dar destinação final ambientalmente adequadas aos pneus inservíveis"; a Resolução 301/2002, "altera dispositivos da Resolução № 258, de 26 de agosto de 1999, que dispõe sobre Pneumáticos". Em 2009, cria-se a CONAMA 416/2009, que "dispõe sobre a prevenção à degradação ambiental causada por pneus inservíveis e sua destinação ambientalmente adequada, e dá outras providências "para revogar as Resoluções n² 258/1999 e n 301/ 2002.

No Brasil, o valor de um pneu inservível no mercado é insignificante, o que dificulta um interesse para a destinação correta. Além desse problema, é proibido descartá-lo em aterro. A única solução é a reforma que só pode ser feita até três vezes para pneus de automóveis de passeio e uma vez para caminhões de carga. (MOTTA, 2008) Quando não há a possibilidade de reformá-lo, deve-se fazer a reciclagem.

A realização deste trabalho se dá pela preocupação em relação aos pneumáticos inservíveis que são descartados de forma incorreta, gerando um aumento dos casos de dengue e o surgimento de animais peçonhentos.

O aumento dos casos de doenças causadas pelo Aedes Aegypti devido ao descarte incorreto dos pneumáticos inservíveis vêm acarretando uma preocupação em relação à destinação final desses pneus.

O gerenciamento público dos pneus inservíveis no município de Volta Redonda é realizado pela Guarda Municipal, que não deveria estar realizando esse gerenciamento, já que esse órgão é responsável pela segurança pública.

Este projeto foi elaborado, buscando-se fundamentar as seguintes questões: no município de Volta Redonda, há alguma preocupação dos órgãos públicos e privados em relação à destinação correta dos pneus inservíveis?

Com o intuito de responder a esse questionamento, a metodologia empregada neste estudo caracteriza-se como exploratória, pois teve por finalidade buscar o que foi produzido sobre o gerenciamento de pneus, no município de Volta Redonda, nos últimos anos. Quanto às técnicas de pesquisa empregadas, destacam-se a pesquisa bibliográfica, estudo de caso e levantamento de campo. A pesquisa bibliográfica adotada delineou seus pilares do conhecimento, por meio da investigação da composição dos pneus, legislações pertinentes, geração de resíduos dos pneumáticos, destinação dos pneus e do processo produtivo. Adiante, o estudo de caso foi ao encontro à revisão literária apresentada, tendo como foco e objeto de estudo, o município de Volta Redonda. Todo esse processo metodológico ocorreu no período de agosto de 2014 a junho de 2015.

Este estudo se justifica devido ao aumento da frota anual de carros na região. De acordo com os dados da Suser (2015), são 125.096 veículos, o que demanda um aumento de obras de infraestrutura no município de Volta Redonda. Há uma preocupação na destinação correta e o reaproveitamento dos pneus, pois, se não forem realizados da forma correta, haverá impactos para a saúde da população. A destinação incorreta poderá levar um tempo de decomposição na natureza indeterminado, gerando um passivo ambiental que é muito agressivo, causado, principalmente, pela queima dos pneus, que é a liberação de produtos químicos tóxicos, com a liberação de óleo pirolítico, que contamina o solo e a 
água, principalmente, o lençol freático, durante 100 anos. Em combustão, o pneu emite também fumaça tóxica, que pode representar riscos de mortalidade prematura, deterioração das funções pulmonares, problemas de coração e depressão do sistema nervoso e central (ANDRIETTA, 2008).

\section{METODOLOGIA}

Para a consolidação deste trabalho, foi realizada pesquisa descritiva de cunho exploratório, que adotou como procedimentos: pesquisa bibliográfica, estudo de caso e pesquisa de campo, por meio da realização de visitas e entrevistas telefônicas.

Foram feitas pesquisas referentes à questão da geração dos resíduos, destinação e disposição, legislações, bem como o gerenciamento dos pneumáticos, vigentes no município de Volta Redonda. Todo esse processo, ocorreu a partir de consultas a diversas fontes de pesquisa: livros, periódicos, sites confiáveis, legislações e normas técnicas.

A fundamentação na estruturação do trabalho subdivide-se em cinco principais componentes: a) identificação do fluxo dos pneus (berço ao túmulo); b) gerenciamento dos pneus no município de Volta Redonda; c) mapeamento das gerações; d) identificação das tecnologias; e) cenário dos geradores.

\section{a. Identificação do Fluxo dos Pneus do Berço ao Túmulo}

No município de Volta Redonda, há uma defasagem em relação à destinação final dos pneus inservíveis, pois não é feita de acordo com que determina a lei. Quando se chega ao fim de sua vida útil, enfrentam-se grandes dificuldades para a sua reciclagem.

Devido à falta de um plano de gerenciamento desses pneus inservíveis, muitos são descartados de forma incorreta. Não há meios de informação da prefeitura para alertar a população nem de como encaminhar esses pneus e o único órgão da prefeitura que tenta solucionar essa problemática é a Guarda Municipal.

Segundo informações cedidas pela RECICLANIP, em 2014, a instituição da ANIP (Associação Nacional da Indústria de Pneumáticos), que realiza o gerenciamento dos pneus, registra que não há um número de pneus comuns e OTRs destinados à reciclagem, devido aos tamanhos variados, pois no descarte, eles não são totalizados de acordo com o seu tamanho e tipo, só havendo a totalização geral do quantitativo dos pneus.

Dos pneus menores, que são destinados juntamente com os de carro de passeio e de caminhão e ônibus, descartados diretamente nos pontos de coleta, em 2013,61,7\% foram para fornos de Cimento e $38,3 \%$ para reciclagem (RECICLANIP, 2014).

$\mathrm{Na}$ figura 1, pode-se observar todo o processo, do berço ao túmulo, do fluxo dos pneus no município de Volta Redonda. 
Figura 1- Fluxograma da destinação dos pneus no município de Volta Redonda

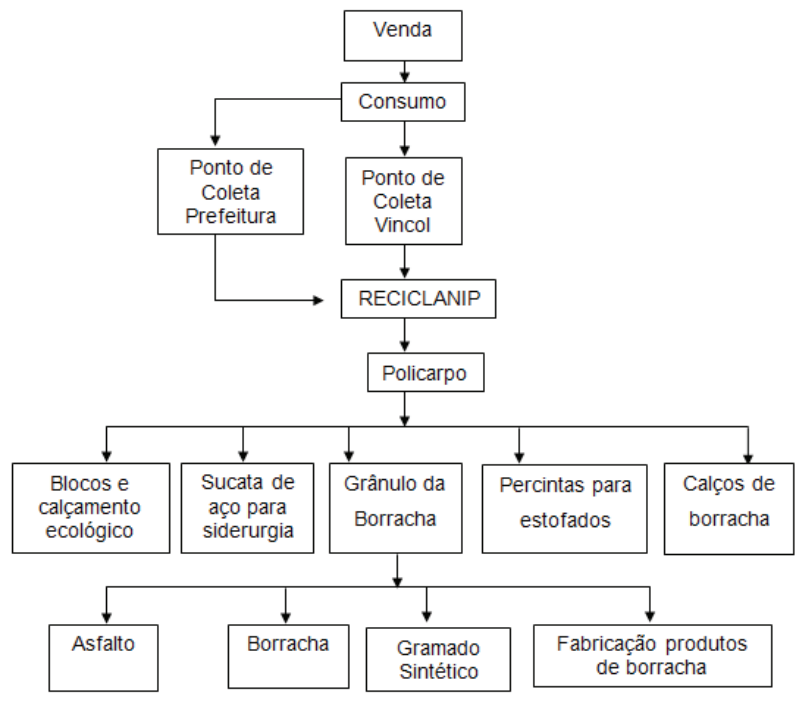

Fonte: Reciclanip, 2014.

Na região, não existe nenhum processo de reciclagem desses pneus, o que acarreta grandes problemas. Eles são encaminhados para São Paulo para serem reciclados e, nesse trajeto, muitos pneus não são enviados devido à dificuldade que os comerciantes e usuários enfrentam em enviá-los para outro estado.

Na região, somente uma empresa, a Vincol, é responsável por armazenar e transportar esses pneus para a empresa recicladora, em São Paulo. Essa empresa, que se localiza em Volta Redonda, não consegue armazenar $100 \%$ desses pneus, devido à alta demanda e à dificuldade enfrentada em aguardar o transporte para esvaziar seu galpão.

A prefeitura, por meio da guarda municipal, armazena os pneus no galpão da guarda municipal e, quando observam que esse galpão está com o espaço lotado, solicita a RECICLANIP para retirar os pneus e dar uma destinação correta.

Além das dificuldades enfrentadas para a reciclagem correta, mencionadas acima, o município de Volta Redonda também enfrenta problemas em relação ao órgão ambiental INEA (Instituto Estadual do Ambiente), que é o responsável por controlar a entrada e saída desses pneus, e também a correta reciclagem, entretanto não fazem esse controle, o que piora a situação para uma correta reciclagem e armazenagem, pois, não havendo fiscalização e controle, eles são descartados de qualquer forma.

\section{b. Gerenciamento dos pneus no município de Volta Redonda}

O gerenciamento dos pneus na região Sul Fluminense iniciou no ano de 2013, pela empresa Goytacazes Pneus, localizada no município de Barra Mansa, onde esses pneus eram retirados pela RECICLANIP e enviados para a Policarpo, mas, no ano de 2014, a empresa Goytacazes foi retirada do credenciamento da Reciclanip, sendo credenciada a empresa recauchutadora Vincol. (RECICLANIP, 2014)

A empresa Vincol faz a coleta dos pneus e a estocagem em um depósito dentro da empresa. Quando é atingido o número suficiente de pneus, a empresa solicita a retirada para a RECICLANIP. A 
empresa Policarpo Reciclagem faz a recepção e o transporte desses pneus para realizar a descaracterização e correta reciclagem, sendo esse processo monitorado pela Reciclanip.

A descaracterização do pneu, realizada pela empresa Policarpo Reciclagem, origina materiais para a confecção de asfalto, borracha, gramado sintético, fabricação de novos produtos de borracha, solas e saltos para borracha, percintas para estofados, calços de borrachas, tapetes, entre outros.

Segundo dados fornecidos pela Vincol, na região, são fornecidos para o mercado interno cerca de 1800 pneus de carga e meia carga e 30 pneus OTRs, por mês. Apesar desse quantitativo e da preocupação de algumas empresas não há programas que incentivam a coleta.

Além desse gerenciamento, existe o gerenciamento realizado pela prefeitura que, atualmente, está sendo realizado pela Guarda Municipal, mas de acordo com o Plano Municipal de Saneamento Básico e Gestão Integrada de Resíduos Sólidos do Município de Volta Redonda, do ano de 2014, no item 5.5.5.5, é registrado que a Secretaria de Serviços Públicos é responsável por armazenar esses pneumáticos. (PLANO MUNICIPAL DE SANEAMENTO BÁSICO E GESTÃO INTEGRADA DE RESÍDUOS SÓLIDOS DO MUNICÍPIO DE VOLTA REDONDA, 2014).

Devido a algumas dificuldades por ter assumido essa responsabilidade, a guarda municipal mantém um depósito para esse fim, localizado no bairro São Luiz. Segundo dados da Guarda Municipal, entre o ano de 2014, que foi quando a guarda assumiu esse compromisso, até janeiro de 2015, foram armazenados 15 mil pneus em seu depósito. (Guarda Municipal de Volta Redonda, 2015)

Os pneus são detectados pela associação de moradores dos bairros que acionam a Guarda Municipal, através da Unidade da Guarda Comunitária (UGC), que foi criada para firmar uma parceria da comunidade com a Guarda, realizando a detecção de pneus que são encaminhados para o depósito.

\section{c. Levantamento de Gerações}

A geração de pneus utilizada neste estudo é de empresas de terraplanagens, transportadoras, indústrias, construtoras e fábricas da região de Volta Redonda com alto potencial de produção e grandes infraestruturas, principalmente aquelas cuja atividade é a de terraplenagem.

De acordo com a figura 2, pode-se observar o quantitativo anual da geração dos pneumáticos gerados no município de Volta Redonda, de acordo com os dados fornecidos pela Reciclanip, do período de 2013 até o primeiro trimestre de 2015 , em toneladas.

Figura 2- Quantitativo de pneus inservíveis no Município de Volta Redonda

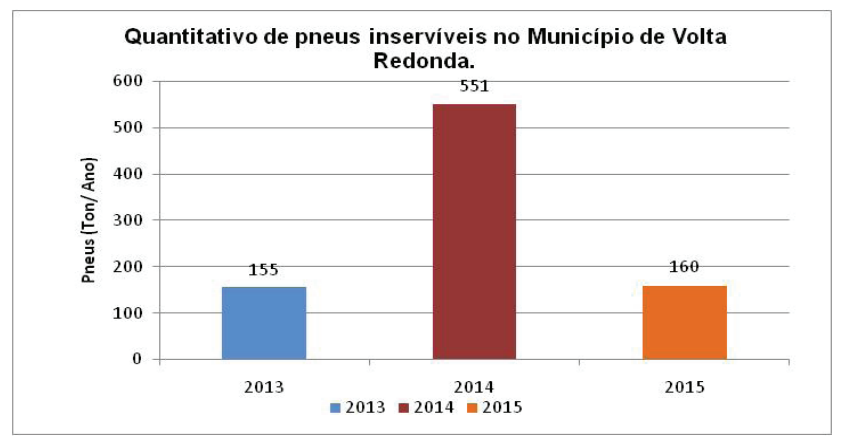

Fonte: Reciclanip, 2015. 
O quantitativo de pneus inservíveis no município de Volta Redonda foi maior, devido ao aumento da frota de veículos, em 2014, e apresentou um valor abaixo, em 2015, pois não foi totalizado o ano todo de 2015 , somente até o mês de março. Por isso, pode-se observar a queda no gráfico.

\section{d. Identificação das Tecnologias}

Quando nos defrontamos com o número de pneus inservíveis gerados anualmente em todo o mundo, percebe-se a importância de se buscar novas alternativas para utilização desse material em outros processos de reaproveitamento e reciclagem. A reinserção da borracha do pneu como matéria-prima para novos produtos, seja na forma inteira (fornos de cimenteiras) ou triturado (granulado para misturas asfálticas), entre outras utilizações, depende de investimentos dos fabricantes em técnicas de manufatura, pesquisa de materiais, estudo sobre formas de reinserção desse resíduo na cadeia produtiva. "[...] Para o desenvolvimento e avanço dessas tecnologias de reutilização e reciclagem de pneus, é necessário um esforço conjunto: empresas, governo e sociedade" (SANDRONI, PACHECO, 2005).

A motivação para as empresas realizarem o processo de reciclagem dos pneus inservíveis não depende apenas da escolha da tecnologia ideal para o processo, mas também de fatores relacionados ao volume de pneus, proximidade de mercado, tipo de consumidores, investimento necessário, além de incentivos fiscais e financeiros (SANDRONI, PACHECO, 2005).

As principais tecnologias utilizadas para a descaracterização e reciclagem dos pneus inservíveis são:'

- Cooprocessamento: os pneus inservíveis são usados como combustível alternativo em fornos de indústria de cimento, substituindo o coque derivado de petróleo;

- Laminação: os pneus são cortados em lâminas, dando origem a produtos como: sola de sapatos e dutos de águas pluviais;

- Asfalto-borracha: os pneus inservíveis são triturados e misturados à massa de asfalto;

- Artefatos de borracha: os produtos confeccionados com os pneus inservíveis são: tapetes para automóveis, pisos industriais, pisos para quadras poliesportivas, revestimento acústico, entre outros.

A figura 3, correlaciona o fluxograma de tecnologias utilizadas para a descaracterização e reciclagem dos pneus inservíveis do município. 
Figura 3- Tecnologias do processo de reciclagem dos pneus

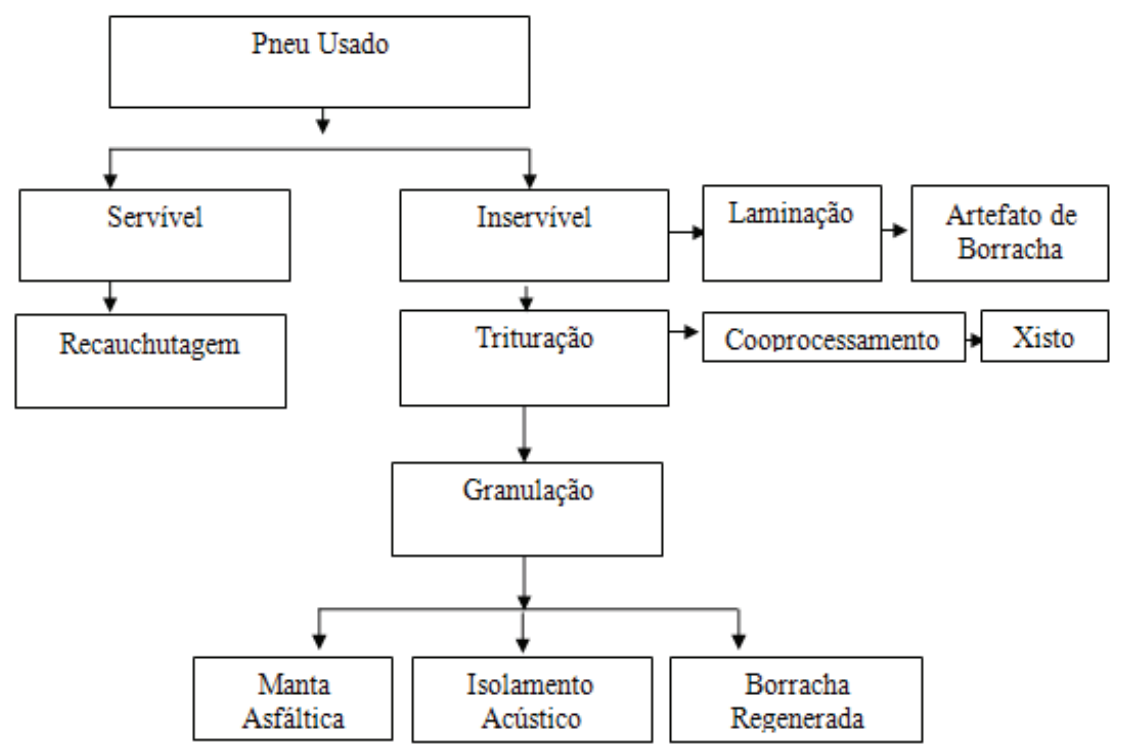

Fonte: Lagarinhos, 2008 adaptado.

\section{e. Cenários dos Geradores}

A região enfrenta uma grande dificuldade no descarte correto, pois somente uma empresa é responsável pela armazenagem desses pneus, atendendo ao público particular e, no serviço público, a Guarda Municipal atende ao público privado, além de exercer a sua função na segurança pública.

A logística de reaproveitamento e reciclagem desses pneus seguem as seguintes etapas, conforme figura 4:

Figura 4- Etapa da logística de reaproveitamento e reciclagem dos pneus.

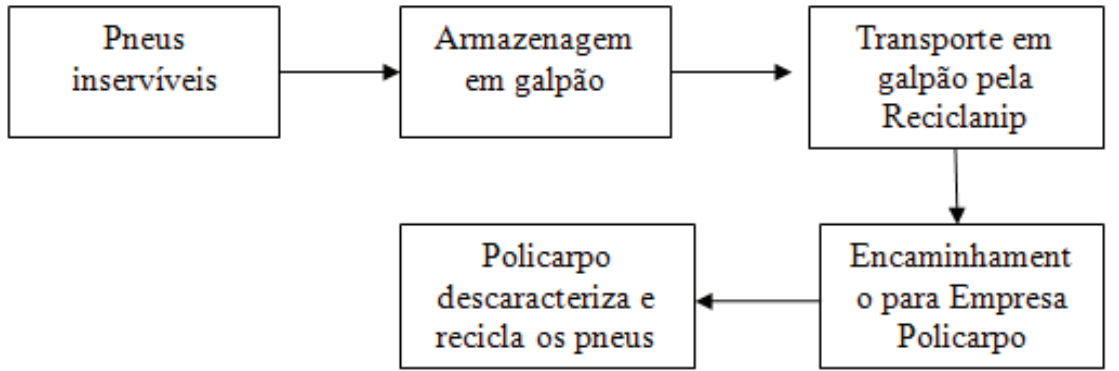

Fonte: Vincol e Guarda Municipal, 2015.

Esse sistema utilizado na região está dificultando a completa reciclagem, entretanto o deslocamento realizado é muito alto, o que dificulta para os comerciantes e usuários cumprir com a logística reversa.

O cenário dos pneumáticos que a Guarda Municipal vêm enfrentando no município de Volta Redonda é cada vez mais preocupante, devido à insistência da população em descartar de forma incorreta os pneus. Apesar da Guarda Municipal estar constantemente informando a população através de mídias, sobre a forma correta para a coleta, algumas empresas insistem em fazer o descarte da forma incorreta em terrenos baldios e a céu aberto. 
Nas figuras 5,6,7 e 8, pode-se observar o trabalho realizado pela Guarda Municipal para a retirada e limpeza desses terrenos no Bairro Conforto.

Figura 5 - Disposição incorreta dos pneumáticos no Bairro Conforto

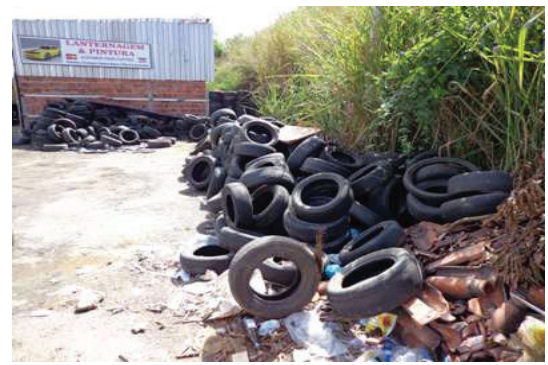

Fonte: Guarda Municipal, 2014

Figura 7 - Disposição incorreta dos pneumáticos no Bairro Belo Horizonte

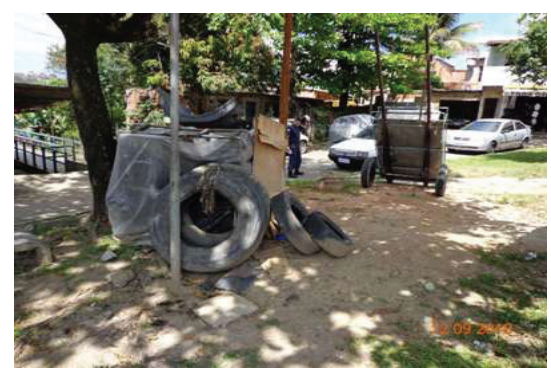

Fonte: Guarda Municipal, 2013.
Figura 6 - Limpeza da área pela Guarda Municipal

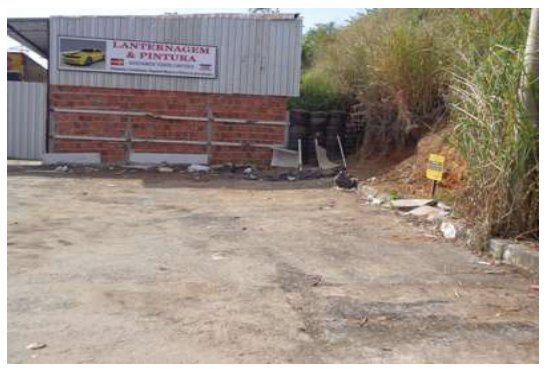

Fonte: Guarda Municipal, 2014.

Figura 8- Limpeza da área pela Guarda Municipal

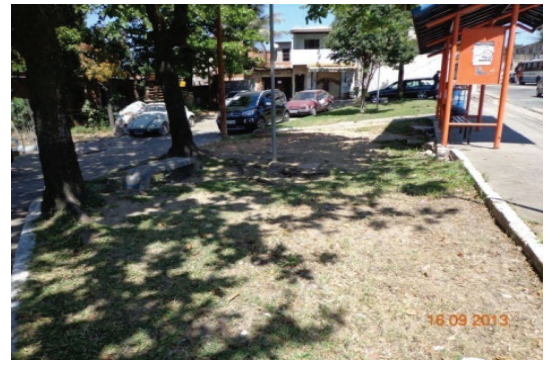

Fonte: Guarda Municipal, 2013.

\section{RESULTADOS}

Levando em consideração os problemas apresentados neste trabalho, foi identificado que o descarte e armazenamento dos pneus não é realizado de acordo com a legislação ambiental (CONAMA 258/99), por meio da logística reversa, englobando a preocupação com o meio ambiente.

No município de Volta Redonda, o gerenciamento público dos pneus inservíveis é realizado pela Guarda Municipal, ao contrário do que determina a Resolução CONAMA 258/99, que determina que as empresas fabricantes e as importadoras de pneumáticos ficam obrigadas a coletar e dar destinação final ambientalmente adequada aos pneus inservíveis.

A Guarda Municipal é responsável por coletar e estocar, no Galpão localizado no Bairro São Luiz, os pneus, além de carros e motos, sendo, também responsável pela destinação final. Se no município de Volta Redonda, em todos os bairros, houvesse Ecopontos para a coleta, facilitaria o trabalho para a Guarda Municipal, pois a população seria informada e os destinaria para esses pontos, facilitando, assim, o trabalho.

De acordo com o Plano Municipal de Saneamento Básico e Gestão Integrada de Resíduos Sólidos do município de Volta Redonda, no item 5.5.5 (Pneumáticos), registra-se que a Secretaria de Serviços Públicos é responsável pela coleta e destinação dos pneus, o que, na realidade, não ocorre, caracterizando que o município não tem um plano de gerenciamento desse material, acarretando, também, 
uma transferência de responsabilidade para a Guarda Municipal, de forma a prejudicar o correto plano de gerenciamento de pneus inservíveis.

Em relação aos pilares da sustentabilidade da ISSO 14001: econômico, social e ambiental, verifica-se que o município de Volta Redonda apresenta um déficit nos três pilares, devido à problemática dos pneus inservíveis. Na parte social, não possui um sistema eficaz de comunicação entre a população, para auxiliar no gerenciamento dos pneus inservíveis. Na elaboração deste trabalho, foram necessárias várias entrevistas e levantamentos de dados com a Secretaria do Meio Ambiente e com a Secretaria de Serviços Públicos, sendo identificado que o gerenciamento dos pneus inservíveis está sendo realizado pela Guarda Municipal. No pilar econômico, há um déficit em relação à verba destinada para o gerenciamento desses pneus. A verba utilizada para a Guarda Municipal é dividida entre a sua função e o gerenciamento desses pneus, dificultando, assim, a eficiência de seu trabalho. No pilar ambiental, não há uma preocupação dos órgãos municipais em relação a esse passivo ambiental, devido às falhas encontradas nesse gerenciamento.

Os gestores não estabelecem um programa de análise de desempenho, não mensuram a realidade dessa geração, apresentando somente valores aproximados, dificultando assim, um valor real e uma análise completa e do problema enfrentado pelo município de Volta Redonda. Esses dados não estão disponíveis para a população ou empresas, conforme registrado no Plano de Gerenciamento de Resíduos Sólidos do município de Volta Redonda, assinado pelo prefeito em 2014. Para obtê-los, foram necessários 6 meses de levantamentos com grandes dificuldades. Tal Plano determina a responsabilidade para a Secretaria de Serviços Públicos, porém ela não a cumpre, desviando para a Guarda Municipal essa função. Por sua vez, a Guarda não consegue levantar dados reais, devido ao desvio de função, utilizando a sua ouvidoria para levantar e auxiliar nesse gerenciamento, sem um conhecimento específico sobre o correto processo. Antes de 2014, o município não tinha um plano de gerenciamento, o que impossibilitou a coleta de dados antigos, desde 2013, com a RECICLANIP, obtendo somente dados da coleta privada da Região.

A prefeitura do município de Volta Redonda não apresenta nenhum plano de treinamento ou programa de melhoria para o gerenciamento dos pneus inservíveis e não existe empresa destinada à reciclagem desses pneumáticos, sendo enviados a empresas em outros Estados.

O INEA, que deveria fazer essa fiscalização e disponibilizar dados referente à destinação desses pneus, não atende esses quesitos. As empresas que deveriam emitir um manifesto de resíduos de pneumáticos inservíveis, para um melhor controle desses materiais, por dificuldade de não ter esses dados, não tem controle, não havendo valores reais para esse gerenciamento, o que acarreta um funcionamento incorreto.

\section{CONCLUSÃo}

A elaboração deste trabalho teve como objetivo verificar se o município de Volta Redonda possui um plano de gerenciamento de pneus inservíveis, conforme determina a Legislação. De acordo com o levantamento realizado, pode-se observar que há uma defasagem em relação ao cumprimento da Legislação e um problema com o gerenciamento dos pneumáticos. Apesar de a prefeitura possuir um Plano de Gerenciamento de Resíduos Sólidos formulado em 2014, que determina que a responsabilidade desse gerenciamento é da Secretaria de Serviços Públicos, os pneumáticos são descartados de forma incorreta. A responsabilidade da coleta, transporte e destinação correta dos pneumáticos é realizada pela Guarda Municipal.

Conclui-se que o município de Volta Redonda enfrenta, nos dias atuais, um problema em relação à logística reversa dos pneumáticos, pois não apresenta empresas na região, para a descaracterização dos pneus e reciclagem dos pneus. Eles são encaminhados para outros estados para serem descaracterizados 
e reciclados, tendo uma grande perda material e um custo alto para a realização desse processo da forma correta, dependendo sempre de uma única empresa para o transporte, reciclagem e descaracterização.

O Plano de Gerenciamento dos Pneumáticos, conforme a Resolução CONAMA 258/1999, deveria ser realizado pelas empresas fabricantes e importadoras de pneumáticos, obrigadas a dar a destinação final aos pneus inservíveis. Deveriam também fazer o recebimento no comércio de distribuidores e revendedores de pneumáticos. E os fabricantes deveriam informar as empresas e a população sobre o ponto de coleta, onde os pneus deveriam ter a sua destinação final.

A gestão ambiental do município de Volta Redonda não segue a Norma CONAMA 258 e 416, fazendo com que a destinação dos pneus inservíveis enfrente grandes obstáculos.

A prefeitura de Volta Redonda, para minimizar essa problemática, deveria criar medidas e programas para ampliar o ciclo de vida desses pneus, por meio da reutilização e reciclagem.

Pode-se concluir que há no município uma defasagem em relação ao plano de gerenciamento dos pneus inservíveis, colocando em risco o bem estar e a saúde da população de Volta Redonda, agravando o problema do passivo ambiental criado na destinação incorreta desses pneus.

Enfım, o gerenciamento não cumpre o que determina a Lei. O Município deveria fazer alguma campanha ou projeto para que as empresas fizessem essa destinação correta, com propostas de criação de empresas de reciclagem na região para evitar o problema.

\section{REFERÊNCIAS}

ANDRIETTA, A, J. Pneus e Meio Ambiente: Um Grande Problema Requer uma Grande. Disponível em: <http://www.reciclarepreciso.hpg.ig.com.br/recipneus. htm>. Acesso em: 17 mar. 2015.

BRASIL. Resolução CONAMA n 416, 20 de setembro de 2009. Prevenção à degradação ambiental causada por pneus inservíveis e sua destinação ambientalmente adequada. Diário oficial da República Federativa do Brasil, Poder Executivo, Brasília, DF, 20 set. 2009.

BRASIL. Resolução CONAMA n 258 , de 26 de agosto de 1999. Determina que as empresas fabricantes e as importadoras de pneumáticos ficam obrigadas a coletar e dar destinação final ambientalmente adequada aos pneus inservíveis. Diário oficial da República Federativa do Brasil, Poder Executivo, Brasília, DF, 26 ago. 1999.

GUARDA MUNICIPAL DE VOLTA REDONDA. Empresa do Rio retira cerca de 15 mil pneus do Depósito da GMVR. Disponível em: <http://www.voltaredonda.rj.gov.br/guardamunicipal/index.php/10-noticias-destaque/163empresa-do-rio-retira-cerca-de-15-mil-pneus-do-deposito-da-gmvr>. Acesso em: 15 abr. 2014.

MOTTA, Flávia Gutierrez. A cadeia de destinação dos pneus inservíveis - o papel da regulação e do desenvolvimento tecnológico. Ambiente \& Sociedade, Campinas, v. 11, n. 1, p. 167-184, jan-jun. 2008.

RECICLANIP. Pontos de Coleta de Pneus no Brasil. Disponível em: <http://www.reciclanip.org.br/v3/ pontos-coleta/brasil>. Acesso em: 15 mar. 2015.

SANDRONI, Mariana. PACHECO, Elen B.A V. O Destino dos Pneus Inservíveis. 2005. Disponível em: <http://www.niead.ufrj.br/artigoelen.htm>. Acesso em: 29 mar. 2015. 